GRASAS Y ACEITES 72 (2)

April-June 2021, e405

ISSN-L: 0017-3495

https://doi.org/10.3989/gya.0220201

\title{
Application of mixed starter culture for table olive production
}

\author{
๑Z.Ş. Erdemir Tıraş and $\oplus H$. Kalkan Yıldırım ${ }^{\mathrm{b}}$, \\ ${ }^{a}$ Olive Research Institute, 35100, Izmir, Turkey \\ ${ }^{\mathrm{b}}$ Ege University, Engineering Faculty, Department of Food Engineering, 35100, Izmir, Turkey \\ ${ }^{\square}$ Corresponding author: hatice.kalkan.yildirim@ege.edu.tr
}

Submitted: 24 February 2020; Accepted: 19 April 2020; Published online: 07 June 2021

SUMMARY: The fermentation of olives is usually carried out spontaneously by natural microbiota. Spontaneous fermentation has some disadvantages, such as the formation of defects in the end product due to the activities of undesirable microorganisms. The use of starter cultures could be a promising option to provide a more controlled fermentation environment and to reduce the risk of spoilage. Mixed starter culture use (generally selected Lactobacillus strains with or without yeasts) could reduce pH in a shorter time, producing a higher amount of lactic acid and enhancing microbial safety compared to fermentation with starter cultures containing single species or natural fermentation. Their use could also enhance the organoleptical properties of table olives. Particularly the use of yeast (such as strains of $W$. anomolus, S. cerevisiae) in the fermentation of olives, in combination or sequentially with lactic acid bacteria could result in an increase in volatile compounds and a more aromatic final product.

KEYWORDS: Controlled fermentation; Mixed starter cultures; Table olive

RESUMEN: Aplicación de un cultivo iniciador mixto para la producción de aceituna de mesa. La fermentación de la aceituna generalmente se lleva a cabo espontáneamente por la microbiota natural. Sin embargo, la fermentación espontánea tiene algunas desventajas, como la formación de defectos en el producto final debido a las actividades de microorganismos indeseables. El uso de cultivos iniciadores podría ofrecerse como una opción importante para proporcionar un entorno de fermentación más controlado y reducir el riesgo de deterioro. El uso de cultivos mixtos iniciadores (cepas generalmente seleccionadas de Lactobacillus con/sin levaduras) podría reducir el pH en un tiempo más corto, produciendo una mayor cantidad de ácido láctico y mejorando la seguridad microbiana, en comparación con la fermentación con cultivos iniciadores que contienen especies individuales o fermentación natural. Su uso también podría mejorar las propiedades organolépticas de las aceitunas de mesa. En particular, el uso de la levadura (como las cepas de $W$. anomolus, S. cerevisiae) en la fermentación de aceitunas, en combinación o secuencialmente con bacterias de ácido láctico podría dar lugar a un aumento de los compuestos volátiles y a la obtención de un producto final más aromático.

PALABRAS CLAVE: Aceituna de mesa; Cultivos iniciadores mixtos; Fermentación controlada

Citation/Cómo citar este artículo: Erdemir Tıraş ZŞ, Kalkan Yıldırım H. 2021. Application of mixed starter culture for table olive production. Grasas Aceites 72 (2), e405. https://doi.org/10.3989/gya.0220201

Copyright: (C2021 CSIC. This is an open-access article distributed under the terms of the Creative Commons Attribution 4.0 International (CC BY 4.0) License. 


\section{INTRODUCTION}

Table olives are regarded as one of the oldest and most popular fermented foods in the world. Due to their rich nutritional components such as monounsaturated fatty acids, antioxidants (e.g $\alpha$-tocopherol) and bioactive compounds (e.g. phenolic substances), table olives are a significant part of the diet and promise health benefits for consumers (Aktan et al., 1999; Sakouhi et al., 2008; Malheiro et al., 2012).

According to the Trade Standard Applying to Table Olives of International Olive Oil Council, table olives are defined as "the sound fruit of varieties of the cultivated olive trees (Olea europea L.), which are chosen for their production of olives when their volume, shape, flesh to-stone ratio, fine flesh, taste, firmness and ease of detachment from the stone make them particularly suitable for processing; treated to remove their bitterness and preserved by natural fermentation; or by heat treatment, with or without the addition of preservatives; packed with or without covering liquid." (IOOC, 2004).

Olive fruits are not suitable food products for direct consumption due to phenolic compounds, particularly oleuropein, which make the fruit taste bitter. For this reason, olives should be processed first in order to hydrolyze oleuropein and remove this bitter taste (Değirmencioğlu, 2016). The most well-known processing methods used in the world are Spanish style, Californian style and natural processing. In Spanish style, olives are immersed in an alkali $(\mathrm{NaOH})$ solution to remove bitterness by chemical hydrolysis of oleuropein (Figure 1) and subjected to fermentation in brine (Johnson et al., 2018). Californian style includes a lye treatment, and the solution is ventilated with the aim of obtaining a dark color through oxidation. In this technique, there is no fermentation step and the olives are preserved by sterilization (Charoenprasert et al., 2014). Natural processed olives are not treated with alkali and are directly fermented into brine (Johnson et al., 2018). Greek style is also a natural processing technique with air in the fermentation step for color improvement (Boskou, 2006). In natural processing, the removal of bitterness is carried out by the diffusion of oleuropein from fruit to brine and the occurrence of non-bitter compounds through enzymatic hydrolysis (Figure 1), namely with the beta-glucosidase and esterase activity found in olives, as well as enzymatic activities of natural microbiota (Ozdemir et al., 2014).

The fermentation of table olives is generally an artisanal process, but the inconsistent end product and spoilage risks exist under these uncontrolled conditions. Starter cultures could be an option for a more controlled fermentation process and a highquality product (Bonatsou et al., 2017). The use of mixed culture in olive production is relatively new and could contribute further to the beneficial effects expected from the use of starter culture. The aim of this review is to present an overview to the studies in which combined cultures were used in table olive production.

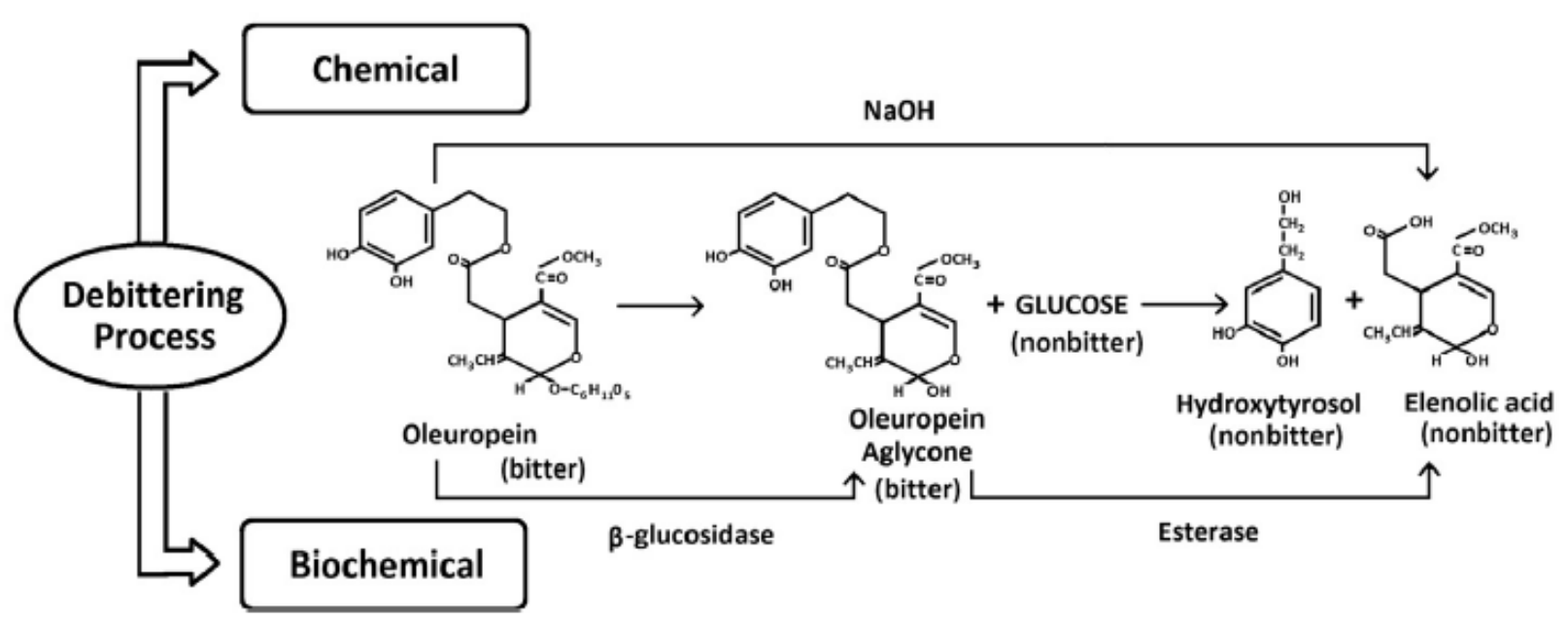

FIGURE 1. Chemical and biochemical hydrolysis of oleuropein (Boskou et al., 2015) 


\section{SPONTANEOUS FERMENTATION OF TABLE} OLIVES

The use of starter cultures is not a common practice in table olive fermentation. The endogenous microbiota of the olive carries out the fermentation process (Heperkan, 2013). The olive microbiota is variable depending upon the processing methods and olive cultivar. In addition, other variables, such as temperature, salt, $\mathrm{pH}$ or geographical zone may affect the microbiota in the olives (Corsetti et al., 2012). Lactic acid bacteria (LAB) and yeasts are the key actors to performing this process (Heperkan, 2013; Tufariello et al., 2016; Bonatsou et al., 2017).

The fermentation stages of table olives could be divided into three time periods. In the first days of fermentation, the $\mathrm{pH}$ level is high, with the value range of 6-11, and Enterobacteriaceae could be the most predominant microbial group. At the same time, some Gram-positive bacteria such as Leuconostoc, Pediococcus or Bacillus spp. are generally present. This step is crucial for ensuring the reduction in $\mathrm{pH}$ level, because if not, the fermentation quality could be affected negatively due to the growth of undesired bacteria which could cause adverse organoleptic properties (Bevilacqua et al., 2015).

After this phase, a reduction in the $\mathrm{pH}$ level and "primary fermentation" begin. LAB ferment the substrates and produce lactic acid; thus $\mathrm{pH}$ reduction and acidification are provided. Lactobacillus species play a major role due to their homofermentative metabolism and high acid production capacity. As the $\mathrm{pH}$ reduces to $5, L$. plantarum and $L$. pentosus predominate. In this way, they also provide microbiological stability by eliminating undesired bacteria through the production of some antimicrobial compounds such as lactic acid, hydrogen peroxide and bacteriocins. The number of Gram-negative bacteria is reduced due to their sensitivity to such an acidic environment. In the last step, which is called as "secondary fermentation", L. plantarum becomes dominant and reduces the pH level below 5 (Hurtado et al., 2012, Bevilacqua et al., 2015). Yeast species, especially some strains of Candida, Pichia and Saccharomyces could also contribute to the flavor formation in table olives by producing some components like glycerol, ethanol, esters, organic acids and aldehydes. Additionally, esterase and lipase activities of the yeast species could increase the free fatty acid content in olives, which in turn could provide the formation of important components for aroma development, such as propanol and 2-butanol. The contribution of yeasts to the fermentation process could also be the degradation of phenolics with their beta-glucosidase activity (Arroyo-López et al., 2008; Bevilacqua et al., 2013; Bonatsou et al., 2015).

Spontaneous fermentation has many drawbacks since it is uncontrollable and unpredicted outcomes can occur. Spoilage microorganisms could grow and cause a final product with undesired quality (Tufariello et al., 2016). For example, in the first stage of the fermentation, if adequate acid levels cannot be reached, Enterobacteriaceae (can grow pH 4.4-9.0) and some other Gram-negative bacteria could grow in high numbers. They could exhaust sugar and produce $\mathrm{CO}_{2}$ causing the formation of gas pockets, which end up softening the olives. Moreover, if $\mathrm{pH}$ levels remain higher than necessary (i.e. 4.2), Clostridium butyricum could bring about butyric and putric fermentation which cause the product to have an unpleasant smell and can crack the fruits (Lanza, 2013). The softening of olive tissue could also stem from the activity of pectolytic yeasts and moulds, which are able to degrade pectic compounds (Arroyo-Lopez, 2012b). When lactic acid fermentation is complete, the $\mathrm{pH}$ level should be lower than 4 to ensure microbiological safety if the product will not be pasteurized. Unless acidity and salt contents (should be over $8 \%$ ) are sufficient, zapatera spoilage could occur due to the actions of Clostridium and Propionibacterium. This is characterized by the production of malodorous organic acids which make the product inconsumable (García et al., 2004). Alcohol fermentation by yeasts and the resultant carbon dioxide, ethanol and organic acids can also cause sensory abnormalities such as the formation of a winey-vinegar taste in olives (Lanza, 2013). The use of starter culture is proposed in order to minimize these problems, which could occur during spontaneous fermentation.

\section{STARTER CULTURE USE IN TABLE OLIVE PRODUCTION}

Starter cultures can be defined as preparations that include microorganisms with desirable metabolic characteristics for the fermentation environment (Heperkan, 2013). The aims that could be achieved with the use of starter cultures can be listed as follows (Bonatsou et al., 2017): 
- obtaining a more controlled fermentation environment

- increasing the initial number of desired microorganisms

- accelerating the de-bittering process

- enhancing the organoleptical properties of the final product

- reducing the risk of spoilage and pathogen growth

- preserving/improving the healthy and nutritional characteristics of the product

- obtaining a final product with extended shelf-life

- providing the food with a functional property, such as probiotic characteristics

Microorganism should have some desired characteristics in order to be selected as starter culture in table olive fermentations. They should degrade phenolic substances to some extent with their beta-glucosidase and esterase activity, grow in high numbers $\left(10^{6}-10^{7} \mathrm{cfu} / \mathrm{ml}\right)$ and predominate in the fermentation environment. They should not be sensitive to high salt concentrations (8-10\%), acidity and phenolics and produce lactic acid in high amounts. They also should have low nutrient requirement and grow at low temperatures. If they are used in commercial application, they should survive in frozen forms (Bevilacqua et al., 2015).

Although Spanish style table olives are normally fermented between 60-120 days, the fermentation of directly brined olives takes much longer, 8-12 months in general, when it is carried out spontaneously. Such a long fermentation period retards the introduction of the product into the market and this is undesirable for manufacturers (Tufariello et al., 2016). Due to their technological superiority, starter cultures could easily colonize into the fermentation medium by eliminating indigenous microbiota, lower the $\mathrm{pH}$ at desired levels in a shorter time and shorten the time that is required for de-bittering (Corsetti et al., 2012).

The use of a starter culture could also be regarded as an alternative to $\mathrm{NaOH}$ in olive debittering (Tufariello et al., 2016). In Spanish style olive processing, when $\mathrm{NaOH}$ is used to remove oleuropein from olives, a considerable amount of phenols is removed, which means a high level of nutritional loss. Additionally, large amounts of water are wasted, which is hazardous for the environment. The use of starter cultures which exert betaglucosidase activity to hydrolyze oleuropein could diminish the need for alkali treatment and provide an advantage from nutritional and environmental perspectives (Chranioti et al., 2018).

The most commonly used starter cultures for table olive production are lactic acid bacteria (Table 1) (Campus et al., 2018).

Yeasts could have dual effects on table olive processing. Firstly, they could spoil the product. Zaragoza et al., (2017) stated that the use of pectolytic $S$. cerevisiae UCDFST 09-448 caused softening and spoilage to Sicilian style green olives. However, the strains of some yeast species could affect olive processing positively and could be chosen as starters (Table 2). Saccharomyces cerevisiae, Wickerhamomyces anomalus, Candida boidinii, $C$. diddensiae, Pichia galeiformis, P. membranifaciens and Kluyveromyces lactis are the most emphasized yeasts in this respect (Arroyo-Lopez et al., 2012a). In a recent study, Ciafardini et al., (2019) revealed the good performance of $C$. diddensiae, C. adriatica and $W$. anomalus in the fermentation of Taggiasca black olives, particularly when the olives are brined with citric acid and $12 \%$ salt concentration. Schaide et al.,

TABLE 1. The most common used LAB starters in the fermentation of olives (adapted from: Campus et al., 2018)

\begin{tabular}{lll}
\hline Most frequently used & Less frequently used & Rarely used \\
\hline Lactobacillus plantarum & Lactobacillus paraplantarum & Enterococcus casseliflavus \\
Lactobacillus pentosus & Lactobacillus casei & Lactobacillus brevis \\
& Lactobacillus paracasei \\
& Leuconostoc mesenteroides \\
Pediococcus acidilactici & Leuconostoc cremoris \\
\hline
\end{tabular}


Application of mixed starter culture for table olive production $\bullet 5$

TABLE 2. The negative and positive impacts of yeasts on the fermentation of olives (adapted from: Arroyo-López et al., 2012b)

\begin{tabular}{ll}
\hline Negative effects & Positive effects \\
\hline Off odors/flavors & $\begin{array}{l}\text { The formation of volatile compounds that are important for flavor } \\
\text { enhancement (with lipase and esterase activity) }\end{array}$ \\
$\mathrm{CO}_{2}$ production and so blister formation on olive & $\begin{array}{l}\text { Biodegredation of phenolic substances with their beta-glucosidase } \\
\text { activity } \\
\text { Toxic protein production that can be effective in inhibiting fungi and } \\
\text { harmful yeasts }\end{array}$ \\
$\begin{array}{l}\text { Clouding of brines } \\
\begin{array}{l}\text { Fruit softening due to enzymes (proteases, xylanases and } \\
\text { pectinases) }\end{array}\end{array}$ & \begin{tabular}{l} 
Promoting the growth of LAB by synthesizing substrates \\
\hline
\end{tabular}
\end{tabular}

(2019) used S. cerevisiae in combination with olive leaf extract in the Spanish style fermentation of olives of the Carrasqueña cultivar. The authors indicated that the use of the yeast strain could have contributed to the sensorial quality of the final product. Some yeast species are also reported to possess probiotic characteristics (Tufariello et al., 2016).

Along with the safety and quality of the products, consumers also care about their usual, intrinsic and traditional sensory characteristics. Preserving the desired quality properties of olives by using commercial starters is not easy. Hence, selecting microorganisms from their own fermentation environment and using the ones with technological properties as starters could be a better approach. These selected autochthonous starters could be more successful at driving fermentation in comparison to the commercial starters because they could easily adapt to the environment and dominate (Campus et al., 2018). To isolate and characterize LAB and yeasts, culture-dependent methods are applied and cultureindependent methods can be used for identification (Heperkan, 2013). Culture-dependent methods are the conventional microbiological methods where molecular techniques are applied; however, the genetic material is directly extracted from the food matrix while applying the culture-independent methods. These methods should be applied attentively in order to select the most proper strains as starters in the production of table olives (Botta et al., 2012).

Papadelli et al., (2015) used autochthonous Leuconostoc mesenteroides subsp. mesenteroides Lm139 and Lactobacillus pentosus DSM 16366 separately as starters in the natural fermentation of black olives of the Kalamon cultivar. They reported a faster acidification, successful lactic acid fermentation, inhibition of Enterobacteriaceae in a shorter time and a more controlled fermentation environment in conditions with a lower level of salt, through the use of starters in comparison to spontaneous fermentation. Panagou et al., (2008) evaluated a commercial $L$. pentosus starter and a $L$. plantarum strain isolated from cassava for the fermentation of the Conservolea black olives. The starter inoculation accelerated the fermentation process, provided a rapid $\mathrm{pH}$ reduction and decreased the number of Gram-negative bacteria, which lowered the risk of spoilage. The authors observed that $L$. pentosus performed better than $L$. plantarum, probably due to the different origin of the latter. It was proposed by authors that the use of starter culture could contribute to quality and produce a safe product with desirable organoleptic properties. A similar study was carried out more recently by using autochthonous L. pentosus B281 in Greek style processing of the same olive cultivar. The use of the starter increased the physiochemical and sensory quality of the final product (Grounta et al., 2016). Marsilio et al., (2005) used a L. plantarum strain which is able to degrade oleuropein and observed that the de-bittering time was reduced; the acidification and good flavor in the fermentation of the Ascolana tenera cultivar green olives were increased. The authors indicated that the panellists had a less bitter and more aromatic taste with the starter.

The use of probiotic strains could also make table olives have a functional property in addition to its nutritional value (Bonatsou et al., 2017). Through the use of a human origin probiotic strain, L. paracasei IMPC2.1, De Bellis et al., (2010) paved the way for producing a new functional food. Besides being a starter culture, the inoculated strain is colonized on the surface and survived in Bella di Cerignola green table olives. Some strains of $L$. pentosus, $L$. plantarum and $L$. paracasei subsp. paracase $i$ were 
isolated from table olives and reported to show probiotic activity along with the starter culture properties (Argyri et al., 2013).

\section{MIXED STARTER CULTURE USE IN TABLE OLIVE PRODUCTION}

The use of starter cultures with desired characteristics is advantageous in order to obtain products with consistent and enhanced qualities. The mixed started culture is used more commonly in the dairy, meat or cereal industries; however, it is less widely used for the production of table olives (Di Cagno et al., 2008). A mixed starter culture may comprise the same microbial group, such as bacteria or a combination of different groups, such as bacteria and yeasts. In fact, most of the spontaneous food fermentations are based on these kinds of combinations and create a product with desirable properties (Hesseltine, 1992; Adebo et al., 2018).

The use of mixed culture starters could have positive effects compared to the use of a single strain. For instance, differentmetabolic pathways could be used by strains due to the synergistic interactions and multiple transformations of substrates. Microorganisms could also adapt better to the fermentation environment by means of these enhanced metabolic processes (Adebo et al., 2018). Such a complex microflora could make the microorganisms more versatile and more robust. There are two main reasons for this situation. Firstly, the microorganisms can interact with each other via a mechanism called quorum sensing (QS). The molecular signals and metabolites could be transferred between the members of microbiota through the QS. Secondly, the metabolic activities that need to be carried out are shared between microorganisms and then merged, which provides a more productive and overall yield (Smid et al., 2013).

The products could lose their unique organoleptic properties and become plain when fermented by a single strain starter. The reason for this could be a decreased microbial flora in the fermentation environment. Mixed cultures could provide improved organoleptic characteristics due to rich biodiversity. They could also contribute to the acidification rate, reduce fermentation time and improve functionality and nutritional quality (Table 3) (Adebo et al., 2018). In olive fermentation, more than one starter culture can be used either sequentially or simultaneously in a combined form.
As LAB, particularly Lactobacillus are the most used starter cultures, there are studies in which the starter culture combinations are formed with the selected Lactobacillus strains. Ruiz-Barba et al., (2012) used two selected L. pentosus starter strains in the Spanish style fermentation of olives. As compared to the uninoculated samples, the paired starter combination served to reduce the $\mathrm{pH}$ level quickly and obtain a higher amount of lactic acid at the end of the fermentation. Starters adapted to the fermentation environment by overwhelming the natural flora. The authors reported that in this regard, the combined starters were more efficient than a single strain starter which they used previously for fermentation. Some of their abilities such as bacteriocin production and survival at high $\mathrm{pH}$ levels, which is particularly important for the Spanish style processing, were important for managing the fermentation. Perpetuini et al., (2018) combined two L. pentosus strains ( $\mathrm{C} 8$ and $\mathrm{C} 11)$ and used this for the Greek style processing of Itrana cultivar olives. LAB growth and the $\mathrm{pH}$ reduction was quicker in inoculated samples compared to uninoculated ones. A complete disappearance of the oleuropein concentration was observed only in inoculated olives after 30 days of fermentation, which shows the high ability of the combined starter in the de-bittering of olives. In a similar study, an undefined mixture of $L$. pentosus strains decreased the processing time of Tonda di Cagliari cultivar olives by 3 months compared to spontaneous fermentation and suppressed the growth of spoilage bacteria (Campus et al., 2017). Chranioti et al., (2018) compared the effects of a commercial starter and a mix of $L$. plantarum strains originating from olives in the fermentation of Conservolea olives, which are processed with a natural fermentation or in accordance with the Spanish style. Regardless of the production type, the number of lactic acid bacteria was higher in the fermentation with mixed starters compared to spontaneous fermentation and the commercial starter. The mixed culture sped up and controlled the fermentation and contributed to obtaining a safe end product with desirable organoleptic characteristics. It was observed that phenolic compounds in the olive flesh diminished during processing, especially with the alkali treatment. The mixed starter use without alkali was advantageous at this point because of the smallest decrease in the phenolic components 
and the highest antioxidant capacity which were obtained in this way. Bitterness was also reduced in the sensory analysis with the mixed starter. Similarly, Campus et al., (2015) fermented Tonda di Cagliari cultivar olives with autochthonous L. plantarum and a combination of $L$. pentosus strains. Along with the good microbiological quality, the hydroxytyrosol was more abundant in inoculated olives when compared to spontaneous fermentation due to the enhanced enzymatic activity executed by the starters. It is a desired feature because hydroxytyrosol is one of the most significant bioactive compounds with antioxidant activity in olives. The antioxidant capacity of the mixed culture fermented samples was also higher than that of single-strain samples during processing. In addition, a more firm and elastic olive

TABLE 3. Improved features of table olives fermented with mixed culture starter cultures

\begin{tabular}{|c|c|c|c|c|}
\hline Olive cultivar & Process conditions & Starter culture combinations & Enhanced beneficial effect & Reference \\
\hline $\begin{array}{l}\text { Nocellara del } \\
\text { Belice }\end{array}$ & Spanish style & L. pentosus OM13-L. coryniformis OM68 & Improved sensory properties & $\begin{array}{l}\text { Aponte } e t \\
\text { al., (2012) }\end{array}$ \\
\hline $\begin{array}{l}\text { Tonda di } \\
\text { Cagliari }\end{array}$ & Directly brined & Undefined mixed culture of L. pentosus & $\begin{array}{l}\text { Better adaptation to the fermenta- } \\
\text { tion environment }\end{array}$ & $\begin{array}{l}\text { Comunian } \\
\text { et al., } \\
(2017)\end{array}$ \\
\hline $\begin{array}{l}\text { Bella di Cerig- } \\
\text { nola }\end{array}$ & Spanish style & $\begin{array}{l}\text { Probiotic L. plantarum c10- L. plantarum } \\
\mathrm{c} 16-L . \text { plantarum } \mathrm{c} 19 \text { with } 0.5 \% \text { glucose }\end{array}$ & $\begin{array}{l}\mathrm{pH} \text { reduction to a safe level } \\
(4.3-4.5) \text {, control of yeast growth, } \\
\text { probiotic characteristic }\end{array}$ & $\begin{array}{l}\text { Perricone et } \\
\text { al., }(2010)\end{array}$ \\
\hline Gemlik & $\begin{array}{l}\text { Gemlik method with } \\
\text { low }(7 \%) \text { salt concen- } \\
\text { tration }\end{array}$ & $\begin{array}{l}\text { L. brevis-Leuconostoc cremoris; L. bre- } \\
\text { vis-L. paramesenteroides; L. brevis- Leu- } \\
\text { conostoc cremoris- L. paramesenteroides }\end{array}$ & $\begin{array}{l}\text { Higher acidity, control of yeast } \\
\text { growth (when L. cremoris is } \\
\text { present in the mixture) }\end{array}$ & $\begin{array}{l}\text { Kumral et } \\
\text { al., (2009) }\end{array}$ \\
\hline $\begin{array}{l}\text { Kalamata } \\
\text { Chaldikis }\end{array}$ & $\begin{array}{l}\text { Alkali treatment, fer- } \\
\text { mentation in low salt } \\
\text { brine }(2.3 \% \mathrm{NaCl} \text {, } \\
32.3 \mathrm{Mm} \mathrm{Ca} \text {-acetate, } \\
33.9 \mathrm{Mm} \mathrm{Ca}-\text { lactate } \\
\text { and } 4 \% \mathrm{NaCl})\end{array}$ & $\begin{array}{l}\text { L. plantarum Lp 15-Lp 20-Lp 28-Lp 40- } \\
\text { Lp } 48\end{array}$ & $\begin{array}{l}\text { Reduction of the fermentation } \\
\text { time, decrease in the risk of Ente- } \\
\text { robacteriaceae spoilage, increase } \\
\text { in hydroxytyrosol and tyrosol } \\
\text { formation, inactivation of E. coli } \\
\text { O157 EDL- } 932 \text { and L. monocyto- } \\
\text { genes ScottA more than } 6 \text { logs } \\
\text { within } \leq 24 \text { hour }\end{array}$ & $\begin{array}{l}\text { Tataridou et } \\
\text { al., (2015) }\end{array}$ \\
\hline $\begin{array}{l}\text { Nocellara } \\
\text { Etnea }\end{array}$ & $\begin{array}{l}\text { Sicilian style without } \\
\text { alkali }\end{array}$ & $\begin{array}{l}\text { L. plantarum UT2.1-L. paracasei N24- } L \text {. } \\
\text { pentosus } \mathrm{TH} 969 ; \text { L. paracasei } \mathrm{N} 24-L . \\
\text { pentosus } \mathrm{TH} 969 ; \text { L. plantarum UT2.1- L. } \\
\text { pentosus } \mathrm{TH} 969 ; \text { L. plantarum UT2.1- L. } \\
\text { paracasei } \mathrm{N} 24\end{array}$ & $\begin{array}{l}\text { Faster acidification, reaching a } \\
\text { high biodiversity that positively } \\
\text { correlates with ester compounds } \\
\text { which give fruity and floral } \\
\text { aromas; preventing Enterobac- } \\
\text { teriaceae growth at the end of } \\
\text { fermentation }\end{array}$ & $\begin{array}{l}\text { Randozzo et } \\
\text { al., (2017), } \\
\text { Randazzo et } \\
\text { al., (2018) }\end{array}$ \\
\hline $\begin{array}{l}\text { Nocellara } \\
\text { Etnea }\end{array}$ & Directly brined & $\begin{array}{l}\text { L. plantarum UT 2.1-probiotic L.paraca- } \\
\text { sei N24 }\end{array}$ & $\begin{array}{l}\text { Accelerating fermentation pro- } \\
\text { cess, higher reduction of } \mathrm{pH} \text {, inhi- } \\
\text { biting Enterobacteriaceae growth, } \\
\text { potential probiotic characteristics } \\
\text { due to high survival rate of the } \\
\text { probiotic strain }\end{array}$ & $\begin{array}{l}\text { Pino et al., } \\
(2018)\end{array}$ \\
\hline $\begin{array}{l}\text { Kalamata } \\
\text { Conservolea }\end{array}$ & Greek style & $\begin{array}{l}\text { Leuconostoc mesenteroides K T5-1- S. } \\
\text { cerevisiae KI 30-16; L. plantarum A } \\
\text { 135-5-Debaryomyces hansenii A 15-44 }\end{array}$ & $\begin{array}{l}\text { Increasing the amount of hy- } \\
\text { droxytyrosol and tyrosol with } \\
\text { sequential inoculation (first yeast, } \\
\text { then LAB), enhanced antioxidant } \\
\text { content } \\
\text { Most aromatic and acceptable } \\
\text { Kalamata olives with co-inocula- } \\
\text { tion of LAB and yeast }\end{array}$ & $\begin{array}{l}\text { Chytiri et } \\
\text { al., (2019) }\end{array}$ \\
\hline $\begin{array}{l}\text { Bella di Cerig- } \\
\text { nola }\end{array}$ & Greek style & $\begin{array}{l}\text { Commercial L. plantarum-W. ano- } \\
\text { malus DiSSPA } 73 \text { (SY); commercial } L . \\
\text { plantarum-W. anomalus DiSSPA73-L. } \\
\text { plantarum DiSSPA1A7-L. pentosus } \\
\text { DiSSPA7(SYL) }\end{array}$ & $\begin{array}{l}\text { Sweeter taste perception and the } \\
\text { highest sensory appreciation for } \\
\text { SYL; increase in some phenolic } \\
\text { and volatile compounds for SY } \\
\text { and SYL }\end{array}$ & $\begin{array}{l}\text { De Angelis } \\
\text { et al., } \\
(2015)\end{array}$ \\
\hline
\end{tabular}


structure was determined for the combined starter use. The authors concluded that the use of mixed autochthonous $L$. pentosus strains could be a cheaper alternative to the commercial starter cultures for industrial use.

While forming the starter culture mixtures, the use of yeast/LAB communities has drawn attention in studies. As stated above, the use of yeast as an adjunct culture could contribute to the survival of LAB and supress the growth of spoilage bacteria and wild yeasts (Hurtado et al., 2012). Tsapatsaris et al., (2004) inoculated Debaryomyces hansenii to the brine 24 and 48 hours before $L$. plantarum, and in the latter case the growth rate of $L$. plantarum reached its maximum level. This could be associated with the formation of substances which are essential for the growth of L. plantarum, such as vitamins. In a similar study, Saccharomyces cerevisiae enhanced the growth of $L$. pentosus in the fermentation of green olives (SegoviaBravo et al., 2007). However, Pistarino et al., (2013) did not observe a statistical difference when they used L. plantarum and S. cerevisiae together for the fermentation of the Taggiasca black olives. Hurtado et al., (2010) studied the use of $C$. diddensiae C6B19, L. plantarum V10A2 and L. pentosus FXMA1, either alone or in combination with L. pentosus 5E3A18 in natural Arbequina table olive fermentation. Microbial quality was enhanced with mixed inoculations when compared to single strain use. This effect was more notable when the yeast strain and $L$. pentosus 5E3A18 were used together. The presence of the yeast strain, alone or in combination with $\mathrm{LAB}$, created a remarkable decrease in the Enterobacteriacea population. The authors advised that $C$. diddensiae C6B19 could be a promising adjuvant starter which could be effective against unwanted wild yeast and pathogen bacteria. De Castro et al., (2002) tried both the simultaneous and sequential use of Enterococcus casseliflavus and L. pentosus in green olive fermentation and got better results in terms of LAB growth when L. pentosus was inoculated 24 hours later than the yeast. De Angelis et al., (2015) observed a rapid and consistent fermentation process with a combined inoculation of some Lactobacillus strains and Wickeramomyces anomalus during the fermentation of the Bella di Cerignola olives.

Yeasts can produce glycoproteins or other toxic proteins which could reduce the need for chemical preservatives, and thus less salty and natural final products could be obtained with the use of yeasts in starter culture mixtures (Arroyo-López, 2012a). Psani et al., (2006) determined the killer activity of some strains of Debaryomyces hansenii and Torulaspora delbrueckii isolated from fermented black olives against some pathogen bacteria/wild yeasts. They revealed their potential use as adjunct cultures for enhancing the quality of the product.

The organoleptic characteristics of table olives are created with the joint contribution of $\mathrm{LAB}$ and yeasts in fermentation. Through the production of ethanol, glycerol, organic acids, esters, aldehydes and free fatty acids, desired aroma and flavor are formed in the olives (Sabatini et al., 2008; Tufariello et al., 2016; Campus et al., 2018). One of the main purposes of creating a mixed starter combination is increasing the organoleptical properties and especially aroma (Benitez-Cabello et al., 2019). Tufariello et al., (2015) used two Italian (Cellina di Nardo and Leccino) and two Greek olive cultivars (Kalamata and Conservolea) and inoculated them with one yeast starter and 63 days later one LAB starter. S. cerevisiae/L. plantarum for Leccino, P. anomala/L. plantarum for Cellina di Nardò, $S$. cerevisiae and L. mesenteroides for Kalamàta, $D$. hansenii and $L$. plantarum for Conservolea were used. As for the inoculated samples, total organic acid (especially lactic and acetic acids) levels were higher or comparable to those of natural fermentations. In the first month of the fermentation aldehydes (herbaceous flavor) were determined markedly, however terpens and higher alcohols became more prominent in the second month. The authors attributed this situation to yeast activity. In the last part of the fermentation esters (fruity notes) were abundant possibly because of enzymes by LAB. The authors emphasized that this sequential inoculation technology enhanced the organoleptic properties of olives and decreased the fermentation time by 9 months. Pino et al., (2019) used L. plantarum F3.3 and $L$. paracase $i$ N24, a potentially probiotic strain after 60 days in the fermentation of Sicilian table olives. They observed a significant increase in volatile compounds, especially for floral and fruity notes with the inoculation of the probiotic strain. Benitez-Cabello et al., (2019) evaluated the volatile compound profile of Spanish style Manzanilla olives. Two L. pentosus, one $L$. plantarum and a yeast strain, $W$. anomalus, were used either separately 
or all together. The most significant result of the study was enhanced volatile compound formation when the yeast existed. Therefore, the authors suggested that creating an inoculum that included yeasts could be promising in order to obtain a more aromatic end product. Grounta et al., (2016) obtained a less acidic taste for Conservolea black olives with co-inoculation of $L$. pentosus B281 and $P$. membranifaciens $\mathrm{M} 3 \mathrm{~A}$, which was more appreciated in the sensory analysis.

Probiotic strain use could enhance the functionality of table olives and produce a final product with positive health benefits. The colonization capacity and formation of biofilms by LAB on the olive surface are significant characteristics in this regard (Argyri et al., 2014). The probiotics used survived during the mixed culture fermentation of Giarraffa and Grossa di Spagna table olives with the selected Lactobacillus strains (Randazzo et al., 2014). Blana et al., (2014) combined potential probiotic L. pentosus B281 and L. plantarum B282 for the production of Halkidiki cultivar table olives according to the Spanish style. The olives were colonized by $L$. pentosus B281 rather than L. plantarum B282. L. plantarum B282 could not colonize the olive surface when $10 \%$ salt concentration was used for brining although it survived in a concentration over $80 \%$ when the $\mathrm{NaCl}$ level was 8\%. Similarly, Pino et al., (2019) reported a better survival of a potentially probiotic strain (L. paracasei $\mathrm{N} 24$ ) at $5 \% \mathrm{NaCl}$ concentration in comparison to $8 \% \mathrm{NaCl}$ when it was sequentially inoculated with a beta-glucosidase positive LAB (L. plantarum F3.3). The authors suggested that this could be a beneficial approach to obtaining functional and less salty olives.

When used together, $\mathrm{LAB}$ and yeasts can also form stable biofilms on the olives' surface. As the biofilms are ingested by consumers, the technological characteristics of the starters and synergy among them gain more importance (Grounta et al., 2014). The co-presence of yeasts and LAB in the biofilm shows that the mixed use of yeasts and LAB could be a good approach, especially when it comes to carrying probiotics to table olives. The mixed biofilm formation could increase their survival rate when they pass through the gastrointestinal tract (ArroyoLópez et al., 2012b). Grounta et al., (2014) reported that L. pentosus B281 and P. membranifaciens M3A could colonize in Halkidiki table olives processed according to the Californian style in high numbers in most of the different conditions of brining. Authors also indicated that $P$. membranifaciens increased the growth rate and colonization capacity of $L$. pentosus B281. In a similar study, although L. pentosus was quite successful in forming biofilm on the surface of Conservolea black olives, P. membranifaciens M3A could not be found in biofilms at the end of fermentation. However, it was reported that the yeast strain provided a milder taste to the product, which could be appreciated by consumers who do not prefer acidic flavors (Grounta et al., 2016).

\section{CONCLUSION AND FUTURE PROSPECTS}

The table olive is a valuable fermented food product due to its nutritional properties, and starter culture technology is a significant biotechnological approach for its processing. With the use of starters, a low-cost, shorter and more controlled fermentation process and a final product with increased shelflife and enhanced organoleptic properties could be obtained (Campus et al., 2018; Bonatsou et al., 2017).

Food fermentations are generally carried out by a mixed microflora and they have a better ecological success in comparison to single strain fermentations (Sieuwerts et al., 2008). By simulating this, mixed starter cultures, sequentially or in combination, could be used and this approach could produce a higher quality, safer product. The results of the research have indicated that mixed culture fermentation has some important advantages in comparison to the single strain and natural fermentations in table olive production. In order to better understand the interactions between the microflora and the progress of the fermentation, and to determine its effects on the final product, more studies should be done in this field.

It has been emphasized that selecting functional starter cultures from their natural environment and using them is a better approach in comparison to using starters originating from different sources. Thus, metabolic activities in the fermentation environment could be enhanced (Chranioti et al., 2018). Therefore, the selection of new strains from olives/fermentation environments and the creation of suitable combinations between microorganisms in order to use them in table olive production would be more prominent in the future. Furthermore, in this way, in accordance with consumer demand, instead of producing a plain, uniform product, traditional 
flavors could be preserved and transferred to the final product. Healthy, functional table olives would also be developed by the use of starter cultures with probiotic or other features, such as vitamin production (Bevilacqua et al., 2015).

The progress in genetic and genomic tools would allow for revealing functional and new mechanisms in order to comprehend the interactions in mixed cultures and their behaviors. New cultivation methods and innovative techniques, such as immobilization could be exploited to develop and disseminate the use of mixed culture starters (Smid et al., 2013). These approaches could be implemented in table olive production by moving this process to a further point.

\section{REFERENCES}

Adebo OA, Njobeh PB, Adeboye AS, Adebiyi JA, Sobowale SS, Ogundele OM, Kayitesi E. 2018. Advances in fermentation technology for novel food products, in Panda SK and Shetty PH (Ed.) Innovations in Technologies for Fermented Food and Beverage Industries, Springer, Cham, pp. 7187. https://doi.org/10.1007/978-3-319-74820-7_4

Aktan N, Kalkan H. 1999. SofralıkZeytin Teknolojisi. Ege Üniversitesi Basimevi, Bornova, Izmir, Turkey.

Angelis M de, Campanella D, Cosmai L, Summo C, Rizzello CG, Caponio F. 2015. Microbiota and metabolome of un-started and started Greektype fermentation of Bella di Cerignola table olives. Food Microbiol. 52, 18-30. https://doi. org/10.1016/j.fm.2015.06.002

Aponte M, Blaiotta G, La Croce F, Mazzaglia A, Farina V, Settanni L, Moschetti G. 2012. Use of selected autochthonous lactic acid bacteria for Spanish-style table olive fermentation. Food Microbiol. 30, 8-16. https://doi.org/10.1016/j. fm.2011.10.005

Argyri AA, Zoumpopoulou G, Karatzas KAG, Tsakalidou E, Nychas GJE, Panagou EZ, Tassou CC. 2013. Selection of potential probiotic lactic acid bacteria from fermented olives by in vitro tests. Food Microbiol. 33, 282-291. https://doi. org/10.1016/j.fm.2012.10.005

Argyri AA, Nisiotou AA, Mallouchos A, Panagou EZ, Tassou CC. 2014. Performance of two potential probiotic Lactobacillus strains from the olive microbiota as starters in the fermentation of heat shocked green olives. Int. J. Food
Microbiol. 171, 68-76. https://doi.org/10.1016/j. ijfoodmicro.2013.11.003

Arroyo-López FN, Querol A, Bautista-Gallego J, Garrido-Fernández A. 2008. Role of yeasts in table olive production. Int. J. Food Microbiol. 128, 189-196. https://doi.org/10.1016/j. ijfoodmicro.2008.08.018

Arroyo-López F, Romero-Gil V, Bautista-Gallego J, Rodríguez-Gómez F, Jiménez-Díaz R, GarcíaGarcía P, Querol A, Garrido-Fernández A. 2012a. Potential benefits of the application of yeast starters in table olive processing. Front. Microbiol. 3, 1-4. https://doi.org/10.3389/ fmicb.2012.00161

Arroyo-López F, Romero-Gil V, Bautista-Gallego J, Rodríguez-Gómez F, Jiménez-Díaz R, GarcíaGarcía P, Querol A, Garrido-Fernández A. 2012b. Yeasts in table olive processing: desirable or spoilage microorganisms? Int. J. Food Microbiol. 160, 42-49. https://doi.org/10.1016/j. ijfoodmicro.2012.08.003

Bellis P de, Valerio F, Sisto A, Lonigro SL, Lavermicocca P. 2010. Probiotic table olives: microbial populations adhering on olive surface in fermentation sets inoculated with the probiotic strain Lactobacillus paracasei IMPC2.1 in an industrial plant. Int. J. Food Microbiol. 140, 6-13. https://doi.org/10.1016/j. ijfoodmicro.2010.02.024

Benítez-Cabello A, Rodríguez-Gómez F, Morales M, Garrido-Fernández A, Jiménez-Díaz R, ArroyoLópez F. 2019. Lactic Acid Bacteria and Yeast Inocula Modulate the Volatile Profile of SpanishStyle Green Table Olive Fermentations. Foods 8 , 280. https://doi.org/10.3390/foods 8080280

Bevilacqua A, Beneduce L, Sinigaglia M, Corbo MR. 2013. Selection of yeasts as starter cultures for table olives. J. Food Sci. 78, 742-751. https:// doi.org/10.1111/1750-3841.12117

Bevilacqua A, De Stefano F, Augello S, Pignatiello S, Sinigaglia M, Corbo M. 2015. Biotechnological innovations for table olives. Int. J. Food Sci. Nutr. 66, 127-131. https://doi.org/10.3109/09637 486.2014.959901

Blana VA, Grounta A, Tassou CC, Nychas GJE, Panagou, EZ. 2014. Inoculated fermentation of green olives with potential probiotic Lactobacillus pentosus and Lactobacillus plantarum starter cultures isolated from industrially fermented 
olives. Food Microbiol. 38, 208-218. https://doi. org/10.1016/j.fm.2013.09.007

Bonatsou S, Benítez A, Rodríguez-Gómez F, Panagou EZ, Arroyo-López, FN. 2015. Selection of yeasts with multifunctional features for application as starters in natural black table olive processing. Food Microbiol. 46, 66-73. https:// doi.org/10.1016/j.fm.2014.07.011

Bonatsou S, Tassou CC, Panagou EZ, Nychas GJE. 2017. Table olive fermentation using starter cultures with multifunctional potential. Microorganisms 5, 30. https://doi.org/10.3390/ microorganisms 5020030

Boskou G, Salta FN, Chrysostomou S, Mylona A, Chiou A, Andrikopoulos, NK. 2006. Antioxidant capacity and phenolic profile of table olives from the Greek market. Food Chem. 94, 558-564. https://doi.org/10.1016/j.foodchem.2004.12.005

Boskou D, Camposeo S, Clodoveo ML. 2015. Table olives as sources of bioactive compounds, in Boskou D (Ed.) Olive and Olive Oil Bioactive Constituents, AOCS Press, Urbana, pp. 217-259. https://doi. org/10.1016/B978-1-63067-041-2.50014-8

Botta C, Cocolin L. 2012. Microbial dynamics and biodiversity in table olive fermentation: culturedependent and-independent approaches. Front. Microbiol. 3, 245. https://doi.org/10.3389/ fmicb.2012.00245

Cagno R di, Surico RF, Siragusa S, De Angelis M, ParadisoA, MinerviniF, De Gara L, GobbettiM. 2008. Selection and use of autochthonous mixed starter for lactic acid fermentation of carrots, French beans or marrows. Int. J. Food Microbiol. 127, 220-228. https://doi.org/10.1016/j.ijfoodmicro.2008.07.010

Campus M, Sedda P, Cauli E, Piras F, Comunian R, Paba A, Daga E, Schirru S, Angioni A, Zurru R, Bandino G. 2015. Evaluation of a single strain starter culture, a selected inoculum enrichment, and natural microflora in the processing of Tonda di Cagliari natural table olives: Impact on chemical, microbiological, sensory and texture quality. LWT-Food Sci. Technol. 64, 671-677. https://doi.org/10.1016/j.lwt.2015.06.019

Campus M, Cauli E, Scano E, Piras F, Comunian R, Paba A, Daga E, Di Salvo R, Sedda P, Angioni A, Zurru R. 2017. Towards controlled fermentation of table olives: lab starter driven process in an automatic pilot processing plant. Food Bioproc. Tech. 10, 10631073. https://doi.org/10.1007/s11947-017-1882-7
Campus M, Değirmencioğlu N, Comunian R. 2018. Technologies and trends to improve table olive quality and safety. Front. Microbiol. 9, 617. https://doi.org/10.3389/fmicb.2018.00617

Castro A de, Montaño A, Casado FJ, Sánchez AH, Rejano L. 2002. Utilization of Enterococcus casseliflavus and Lactobacillus pentosus as starter cultures for Spanish-style green olive fermentation. Food Microbiol. 19, 637-644. https://doi.org/10.1006/fmic.2002.0466

Charoenprasert S, Mitchell A. 2014. Influence of California-style black ripe olive processing on the formation of acrylamide. J. Agric. Food Chem. 62, 8716-8721. https://doi.org/10.1021/ jf5022829

Chranioti C, Kotzekidou P, Gerasopoulos D. 2018. Effect of starter cultures on fermentation of naturally and alkali-treated cv. Conservolea green olives. LWT-Food Sci. Technol. 89, 403408. https://doi.org/10.1016/j.lwt.2017.11.007

Chytiri A, Tasioula-Margari M, Bleve G, Kontogianni VG, Kallimanis A, Kontominas MG. 2019. Effect of different inoculation strategies of selected yeast and LAB cultures on Conservolea and Kalamàta table olives considering phenol content, texture, and sensory attributes. J. Sci. Food Agric. 100, 926-935. https://doi.org/10.1002/jsfa.10019

Ciafardini G, Zullo BA. 2019. Use of selected yeast starter cultures in industrial-scale processing of brined Taggiasca black table olives. Food Microbiol. 84, 103-250. https://doi.org/10.1016/j. fm. 2019.103250

Comunian R, Ferrocino I, Paba A, Daga E, Campus M, Di Salvo R, Cauli E, Piras F, Zurru R, Cocolin L. 2017. Evolution of microbiota during spontaneous and inoculated Tonda di Cagliari table olives fermentation and impact on sensory characteristics. LWT Food Sci. Technol. 84, 6472. https://doi.org/10.1016/j.lwt.2017.05.039

Corsetti A, Perpetuini G, Schirone M, Tofalo R, Suzzi G. 2012. Application of starter cultures to table olive fermentation: an overview on the experimental studies. Front. Microbiol. 3, 248. https://doi.org/10.3389/fmicb.2012.00248

Değirmencioğlu, N. 2016. Modern techniques in the production of table olives, in Boskou D and Clodoveo MK (Ed.) Products from Olive Tree, IntechOpen, pp. 215. https://doi. org/10.5772/64988 
García PG, Barranco CR, Durán-Quintana MC, Fernández AG. 2004. Biogenic amine formation and "zapatera" spoilage of fermented green olives: effect of storage temperature and debittering process. J. Food Prot. 67, 117-123. https://doi. org/10.4315/0362-028X-67.1.117

Grounta A, Panagou EZ. 2014. Mono and dual species biofilm formation between Lactobacillus pentosus and Pichia membranifaciens on the surface of black olives under different sterile brine conditions. Ann. Microbiol. 64, 1757-1767. https://doi.org/10.1007/s13213-014-0820-4

Grounta A, Doulgeraki AI, Nychas GJE, Panagou EZ. 2016. Biofilm formation on Conservolea natural black olives during single and combined inoculation with a functional Lactobacillus pentosus starter culture. Food Microbiol. 56, 3544. https://doi.org/10.1016/j.fm.2015.12.002

Heperkan D. 2013. Microbiota of table olive fermentations and criteria of selection for their use as starters. Front. Microbiol. 4, 143. https:// doi.org/10.3389/fmicb.2013.00143

Hesseltine, CW. 1992. Mixed Culture Fermentations. Applications of Biotechnology in Traditional Fermented Foods. Applications of Biotechnology in Traditional Fermented Foods, National Academies Press, Washington, Available from: https://www. ncbi.nlm.nih.gov/books/NBK234678/

Hurtado A, Reguant C, Bordons A, Rozès N. 2010. Evaluation of a single and combined inoculation of a Lactobacillus pentosus starter for processing cv. Arbequina natural green olives. Food Microbiol. 27, 731-740. https://doi.org/10.1016/j.fm.2010.03.006

Hurtado A, Reguant C, Bordons A, Rozès N. 2012. Lactic acid bacteria from fermented table olives. Food Microbiol. 31, 1-8. https://doi. org/10.1016/j.fm.2012.01.006

IOOC 2004. Trade Standard Applying to Table Olives. International Olive Oil Council COI/T20/ Doc No 1. Madrid: IOOC.

Kumral A, Basoglu F, Sahin I. 2009. Effect of the use of different lactic starters on the microbiological and physicochemical characteristics of naturally black table olives of Gemlik cultivar. $J$. Food Process. Pres. 33, 651-664. https://doi. org/10.1111/j.1745-4549.2008.00303.x

Johnson RL, Mitchell AE. 2018. Reducing Phenolics Related to Bitterness in Table Olives. J. Food Qual. 1-12. https://doi.org/10.1155/2018/3193185
Lanza B. 2013. Abnormal fermentations in tableolive processing: microbial origin and sensory evaluation. Front. Microbiol. 4, 1-7. https://doi. org/10.3389/fmicb.2013.00091

Malheiro R, Casal S, Sousa A, De Pinho PG, Peres AM, Dias LG, Bento A, Pereira J. 2012. Effect of cultivar on sensory characteristics, chemical composition, and nutritional value of stoned green table olives. Food Bioproc. Tech. 5, 1733-1742. https://doi.org/10.1007/s11947-011-0567-x

Marsilio V, Seghetti L, Iannucci E, Russi F, Lanza B, Felicioni M. 2005. Use of a lactic acid bacteria starter culture during green olive (Olea europaea $\mathrm{L}$ cv Ascolana tenera) processing. J. Sci. Food Agr. 85, 1084-1090. https://doi.org/10.1002/jsfa.2066

Ozdemir Y, Guven E, Ozturk A. 2014. Understanding the characteristics of oleuropein for table olive processing. J. Food Process Technol. 5, 1000328. https://doi.org/10.4172/2157-7110.1000328

Panagou EZ, Schillinger U, Franz CM, Nychas GJE. 2008. Microbiological and biochemical profile of cv. Conservolea naturally black olives during controlled fermentation with selected strains of lactic acid bacteria. Food Microbiol. 25, 348-358. https://doi.org/10.1016/j.fm.2007.10.005

Papadelli M, Zoumpopoulou G, Georgalaki M, Anastasiou R, Manolopoulou E, Lytra I, Papadimitriou K, Tsakalidou E. 2015. Evaluation of Two Lactic Acid Bacteria Starter Cultures for the Fermentation of Natural Black Table Olives (Olea europaea L cv. Kalamon). Pol. J. Microbiol. 64, 265-271. https://doi. org/10.5604/01.3001.0009.2121

Perpetuini G, Caruso G, Urbani S, Schirone M, Esposto S, Ciarrocchi A, Prete R, GarciaGonzalez N, Battistelli N, Gucci R, Servili M, Tofalo R, Corsetti A. 2018. Changes in polyphenolic concentrations of table olives (cv. Itrana) produced under different irrigation regimes during spontaneous or inoculated fermentation. Front. Microbiol. 9, 1287. https:// doi.org/10.3389/fmicb.2018.01287

Perricone M, Bevilacqua A, Corbo MR, Sinigaglia M. 2010. Use of Lactobacillus plantarum and glucose to control the fermentation of "Bella di Cerignola" table olives, a traditional variety of Apulian region (southern Italy). J. Food Sci. 75, 430-436. https://doi.org/10.1111/j.17503841.2010.01742.x 
Pino A, De Angelis M, Todaro A, Van Hoorde K, Randazzo CL, Caggia C. 2018. Fermentation of Nocellara Etnea table olives by functional starter cultures at different low salt concentrations. Front. Microbiol. 9, 1125. https://doi.org/10.3389/ fmicb.2018.01125

Pino A, Vaccalluzzo A, Solieri L, Romeo F, Todaro A, Caggia C, Arroyo-López F, Bautista-Gallego J, Randazzo C. 2019. Effect of Sequential Inoculum of Beta-Glucosidase Positive and Probiotic Strains on Brine Fermentation to Obtain Low Salt Sicilian Table Olives. Front. Microbiol. 10, 174. https://doi.org/10.3389/fmicb.2019.00174

Pistarino E, Aliakbarian B, Casazza AA, Paini M, Cosulich ME, Perego P. 2013. Combined effect of starter culture and temperature on phenolic compounds during fermentation of Taggiasca black olives. Food Chem. 138, 2043-2049. https://doi.org/10.1016/j.foodchem.2012.11.021

Psani M, Kotzekidou P. 2006. Technological characteristics of yeast strains and their potential as starter adjuncts in Greek-style black olive fermentation. World J. Microb. Biot. 22, 13291336. https://doi.org/10.1007/s11274-006-9180-y

Randazzo CL, Todaro A, Pino A, Pitino I, Corona O, Mazzaglia A, Caggia C. 2014. Giarraffa and Grossa di Spagna naturally fermented table olives: effect of starter and probiotic cultures on chemical, microbiological and sensory traits. Food Res. Int. 62, 1154-1164. https://doi.org/10.1016/j. foodres.2014.05.056

Randazzo CL, Todaro A, Pino A, Pitino I, Corona O, Caggia C. 2017. Microbiota and metabolome during controlled and spontaneous fermentation of Nocellara Etnea table olives. Food Microbiol. 65, 136-148. https://doi.org/10.1016/j.fm.2017.01.022

Randazzo CL, Russo N, Pino A, Mazzaglia A, Ferrante M, Conti GO, Caggia C. 2018. Effects of selected bacterial cultures on safety and sensory traits of Nocellara Etnea olives produced at large factory scale. Food Chem. Toxicol. 115, 491-498. https://doi.org/10.1016/j.fct.2018.03.045

Ruiz-Barba JL, Jiménez-Díaz R. 2012. A novel Lactobacillus pentosus-paired starter culture for Spanish-style green olive fermentation. Food Microbiol. 30, 253-259. https://doi.org/10.1016/j. fm.2011.11.004

Sabatini N, Mucciarella MR, Marsilio V. 2008. Volatile compounds in uninoculated and inoculated table olives with Lactobacillus plantarum (Olea europaea L., cv. Moresca and Kalamata). LWT- Food Sci. Technol. 41, 20172022. https://doi.org/10.1016/j.lwt.2007.12.002

Sakouhi F, Harrabi S, Absalon C, Sbei K, Boukhchina S, Kallel H. 2008. $\alpha$-Tocopherol and fatty acids contents of some Tunisian table olives (Olea europea L.): Changes in their composition during ripening and processing. Food Chem. 108, 833-839. https://doi.org/10.1016/j. foodchem.2007.11.043

Schaide T, Cabrera-Bañegil M, Pérez-Nevado F, Esperilla A, Martín-Vertedor D. 2019. Effect of olive leaf extract combined with Saccharomyces cerevisiae in the fermentation process of table olives. J. Food Sci. Technol. 56, 3001-3013. https://doi.org/10.1007/s13197-019-03782-x

Segovia-Bravo KA, López FA, García PG, Quintana MD, Fernández AG. 2007. Treatment of green table olive solutions with ozone. Effect on their polyphenol content and on Lactobacillus pentosus and Saccharomyces cerevisiae growth. Int. J. Food Microbiol. 114, 60-68. https://doi. org/10.1016/j.ijfoodmicro.2006.09.032

Sieuwerts S, De Bok FA, Hugenholtz J, van Hylckama-Vlieg JE. 2008. Unraveling microbial interactions in food fermentations: from classical to genomics approaches. Appl. Environ. Microbiol. 74, 4997-5007. https://doi. org/10.1128/AEM.00113-08

Smid EJ, Lacroix C. 2013. Microbe-microbe interactions in mixed culture food fermentations. Curr. Opin. Biotech. 24, 148-154. https://doi. org/10.1016/j.copbio.2012.11.007

Tataridou M, Kotzekidou P. 2015. Fermentation of table olives by oleuropeinolytic starter culture in reduced salt brines and inactivation of Escherichia coli O157: $\mathrm{H} 7$ and Listeria monocytogenes. Int. J. Food Microbiol. 208, 122-130. https://doi. org/10.1016/j.ijfoodmicro.2015.06.001

Tsapatsaris S, Kotzekidou P. 2004. Application of central composite design and response surface methodology to the fermentation of olive juice by Lactobacillus plantarum and Debaryomyces hansenii. Int. J. Food Microbiol. 95, 157-168. https://doi.org/10.1016/j.ijfoodmicro.2004.02.011

Tufariello M, Durante M, Ramires F, Grieco F, Tommasi L, Perbellini E, Falco V, TasioulaMargari M, Logrieco A, Mita G, Bleve 
G. 2015. New process for production of fermented black table olives using selected autochthonous microbial resources. Front. Microbiol. 6, 1-15. https://doi.org/10.3389/ fmicb.2015.01007

Tufariello M, Mita G, Bleve G. 2016. Biotechnology can improve a traditional product as table olives, in Boskou D and Clodoveo MK (Ed.) Products from Olive Tree, IntechOpen, pp. 235-260. https:// doi.org/10.5772/64687

Zaragoza J, Bendiks Z, Tyler C, Kable M, Williams T, Luchkovska Y, Chow E, Boundy-Mills K, Marco M. 2017. Effects of exogenous yeast and bacteria on the microbial population dynamics and outcomes of olive fermentations. mSphere. 2, 00315-316. https://doi.org/10.1128/mSphere.00315-16 